\title{
Research on Network Security and Privacy Protection in the Background of Big Data
}

\author{
Yong Liu* , Xueyong Li \\ Logistics Centre Hengyang Tobacco Company, Hengyang City, 421000, China \\ *corresponding author
}

Keywords: Big Data Background, Network Security, Privacy Protection, Research and Analysis, Discussion and Summary

\begin{abstract}
We now live in an information age, the prosperity of this information age is not transferred by the will of anyone, so everyone should actively devote themselves to it and draw the corresponding nutrition from this era. But the big data era also breeds a lot of problems, among which network security and privacy protection are extremely serious problems, worthy of the whole society, all Internet users attach great importance to it. The network is not a place outside the law, any person who uses the Internet, should strictly abide by the network regulations, laws and regulations, so that self-become a self-conscious implementation of regulations, reasonable exercise of rights of citizens, thus enjoying the welfare of the times.
\end{abstract}

\section{Brief Analysis of the Network World in the Background of Big Data}

The man who knows the times is a good man. True outstanding figures know how to rely on the development and progress of the times, constantly forward, so as to achieve a better self. For the citizens of the 21st century living in the information age, it is necessary to make use of the Internet technology attentively, so that the Internet technology can bring more convenience to themselves. At present, human beings have entered the era of big data, with information and data, how should human beings be at their own disposal in the face of so much data and information? How exactly should the convenience of the times be used? This is a question worth pondering, but also an urgent question to answer.

\subsection{Information Shed}

Internet users who love the Internet have an overwhelming feeling about the information coming in. Many netizens bear a lot of information, quite heavy and oppressive, because in the face of this explosion of information, many people feel overwhelmed. How can more people get a respite from the complex ocean of information? This is an urgent problem to be solved. There is no doubt that the big data era is a double-edged sword, which not only brings rare opportunities, but also brings a lot of troubles to people. Information explosion is a remarkable feature of the big data era. How to resolve the problems caused by information explosion is a good problem that people should solve. As shown in Table 1, most Internet users are faced with complex information, do not know what information should be chosen from it, let alone how to use good information to serve themselves:

Table 1 Relevant questionnaires

\begin{tabular}{|c|c|}
\hline \multicolumn{2}{|c|}{ In the face of the big data era, what kind of inner experience do you have? } \\
\hline Think that the big data era has enriched life & $38.89 \%$ \\
\hline $\begin{array}{c}\text { The big data era brings a lot of bubble } \\
\text { information }\end{array}$ & $61.11 \%$ \\
\hline
\end{tabular}

\subsection{Mixed Truth and Falsehood}

The information age under the background of big data is not only full of information and information, but also true and false. In the face of the information between truth and falsehood, many people put their time and energy into the identification of truth and falsehood. Even if 
netizens get real information, they also spend a lot of time and energy, which is not worth the gain[1]Therefore, how to use information, how to distinguish information and how to make netizens achieve better development with the help of information is a major problem. Nowadays, many netizens are disturbed by false information, because of the false information and produce an unprecedented sense of anxiety and anxiety, these feelings of anxiety and anxiety are extremely unfavorable to a person's development. At the same time, when a person gets a lot of false information, it is also easy to produce panic and anxious psychology, such a psychological state also has a negative impact on the construction of a civilized and harmonious society. Rumors often come from the Internet, and the harm caused by the spread of rumors to society can not be explained clearly. Analyzing from table 2, many people are faced with such hard-to-determine information and do not know how to deal with it:

Table 2 Relevant questionnaires

\begin{tabular}{|c|c|}
\hline Can you easily identify the truth and falsehood of network information? \\
\hline Yes & $3.45 \%$ \\
\hline Hard & $96.55 \%$ \\
\hline
\end{tabular}

\subsection{Vulnerability to Interference From the Network World}

In the era of big data, people can not survive without information, which also leads many people to be disturbed by the network world, and even give in to their real life. In other words, the virtual network has encroached on the real life, so that people's life into a huge trap and chaos. Especially for younger children, it is easy to be controlled by information technology, unable to sort out the way forward for themselves, and easy to trigger a spat with others on the Internet. The so-called network violence is absolutely not empty talk, in the network world, everyone is likely to become the perpetrator, everyone is also likely to be the victim, so how to defend the rights and interests of self and others, this is an important topic for all Internet users, and for all Chinese Internet users, it is important to make clear the direction and conduct of self in the era of big data, know what to do and what not to do, which is also important for building a harmonious and stable network world.

\subsection{Personal Privacy is Easily Disclosed}

The speed of the development of the Internet and the speed of people's acceptance is astounding, but the many problems caused are also easy to panic, one of which is that personal information is prone to leak problems, if a person's personal information is leaked, destined to trigger a great disaster, so for anyone to protect their own information and privacy in the process of Internet access, is one of the best capabilities. In the network is the world's powerless people have, aggressive people have, the most vicious people have, the people with ulterior motives have, in the face of these different kinds of people, how can we defend the rights and interests of good and kind ordinary people? In the face of human flesh search and other machines, how can a person protect themselves and others' privacy and privacy? This is a question worth thinking about[2]Many people are concerned about the disclosure of their personal information, resulting in serious personal losses, as analyzed in Table 3:

Table 3 Relevant questionnaires

\begin{tabular}{|c|c|}
\hline Has your personal information ever been compromised on the Internet? \\
\hline Yes & $89.76 \%$ \\
\hline No & $10.24 \%$ \\
\hline
\end{tabular}

\section{How Should Defend Cybersecurity and Privacy in the Context of Big Data}

\subsection{Improve the Basic Qualities of Every Netizen}

The network world is not virtual, it is constructed by every individual in the real world, in other words, the group magic dance of the network world is composed of the real devils and devils. If you want to purify the network environment, so that Internet users can feel the refreshing network, make 
good use of the network, we must improve the basic quality of each Internet user, so that each Internet user consciously observe discipline, know how to defend their own interests, while not violating the interests of others, only in this way, can make each of them present a state of "arbitrary, do not exceed the moment ". Under the background of big data, Internet users should strictly demand themselves, defend their legitimate rights and interests, do not spread rumors, do not believe in rumors, do not spread rumors, do not disclose other people's information, do not cause network violence, do not use dirty language, know how to respect others, more know how to respect themselves. To test the civilization degree of a country, we should not only look at the century performance of the national in daily life, but also carefully observe the performance and action of the national in the network world.

\subsection{Introduction of Network Treaties and Norms to Each Individual}

There are no rules, no rules, no rules for anyone should have rules and norms to regulate themselves, control themselves, adjust themselves, so that they become a more social attributes of the individual. In the process of purifying the network environment, we should constantly improve the network convention, so that everyone living in the era of big data can enjoy the convenience of the network, and can consciously resist the negative factors of the network world, so as to become a more disciplined Internet user. Naturally, these conventions themselves should be constantly improved, repaired and improved, so that the network convention can be deeply rooted in the hearts of the people, but the network convention has the basic composition, can not spread obscene content, can not spread false information, can not create social panic, can not cause public opinion contradictions, thus, the whole society can use the network in the state of clearing the wind, building a healthier network world.[3].

\subsection{Improving the Corresponding Laws and Regulations}

China is a country that runs the country according to law in an all-round way. For all Chinese people, they should be a good citizen who obeys the law and does not know how to abide by the law. The network world is not a place outside the law, we should constantly improve the corresponding laws and systems, clarify the responsibilities and rights of Internet users, so that Internet users know more how to use the Internet, how to develop themselves on the Internet, improve themselves, so that they become a better Internet user.

\subsection{Resolutely Crack Down on Illegal and Criminal Acts}

Both morality and law can maintain the harmony and stability of a society, but it is not enough to have morality without law, and it is not enough to have laws that can not ensure implementation. Therefore, after completing the legislative work, we should also ensure that the law is strictly enforced and the law is prosecuted. For anyone who spreads false information on the Internet, for anyone who carries out cyber violence on the Internet, for anyone who spreads obscene and pornographic information on the Internet, for anyone who commits violent crimes through the Internet, there should be serious punishment and crackdown by the relevant departments, so that everyone who uses the Internet can not create chaos through the Internet, and can not create social panic through the Internet, which should be a matter of consensus.

\section{Conclusion}

Under the background of big data, any citizen who is used to the Internet will face the complicated information, which is difficult to distinguish between true and false. For this information, netizens should improve their awareness of self-identification, do not spread rumors, do not create social panic, and should abide by the law and defend the network convention. Any netizen should coordinate the rights and interests of themselves and others on the Internet, resolutely fight against illegal and criminal acts, at the same time, should strictly demand themselves, can not be unfettered in the world of the Internet, should know how to respect the privacy of others, naturally should also defend the privacy of the self. Only to be a person who 
respects himself and others can be accepted by the network.

\section{References}

[1] Li, Hongliang., Gai, Xingjie., Li, Lu. Influencing factors and preventive measures of computer network security technology. Electronic Technology and Software Engineering, no. 24, pp. 188, 2018.

[2] Sun, Haiyong., Li, Qingwei. A Study on Factors and Preventive Measures Affecting Computer Network Security. Digital Technology and Applications, no. 07, pp. 205-206, 2017.

[3] Qiming. E-Commerce Practical Course. Beijing: Higher Education Press, 2018. 